\title{
The Role of Learners' Attitudes Toward Parental Involvement in L2 English Learning
}

\author{
Jung-Tae Kim ${ }^{1} \&$ Rusty Barrett ${ }^{2}$ \\ ${ }^{1}$ Department of English Language \& Literature, Incheon National University, Incheon, South Korea \\ ${ }^{2}$ Department of Linguistics, University of Kentucky, Lexington, KY, USA \\ Correspondence: Jung-Tae Kim, Department of English Language \& Literature, Incheon National University, \\ 119 Academy-ro, Songdo-dong, Yeonsu-gu, Incheon, South Korea.
}

Received: August 26, $2018 \quad$ Accepted: December 1, 2018 Online Published: December 6, 2018
$\begin{aligned} & \text { doi: 10.5539/elt.v12n1p18 } \\ & \text { URL: https://doi.org/10.5539/elt.v12n1p18 }\end{aligned}$

\begin{abstract}
This paper seeks to examine Korean EFL learners' perceptions of parental involvement and how their attitudes toward parental involvement are associated with the success of parental involvement. Two hundred fifty four EFL children in South Korea participated in a survey asking the degree of their parent's involvement in seven involvement types and their attitudes towards parental involvement. The results showed that while all types of parental involvement were positively correlated with English proficiency for the group of children with positive attitudes towards parental involvement, no such correlations were found for the group of children with highly negative attitudes. In addition, for the group of children with moderately negative attitudes toward parental involvement, only less direct, autonomy-supportive parental involvement was found to be related to their achievement. These results suggest that learners' attitudes toward parental involvement may be a factor that delimits the positive influence of parental involvement on EFL learners' achievement.
\end{abstract}

Keywords: attitudes, EFL, foreign language learning, language learning environment, learner variables, motivation, parental involvement, parents

\section{Introduction}

Studies validating the importance of parental involvement in children's academic achievement are ubiquitous (for reviews, see Driessen, Smit, \& Sleegers, 2005; Jeynes, 2010). It is clear that both different types of parental involvement (Pomerantz, Moorman, \& Litwach, 2007) and different types of parenting styles (Lamborn, Mounts, Steignberg, \& Donbusch, 1991) may influence the degree to which parental involvement correlates with academic achievement. Research has demonstrated that parental involvement varies across cultures. For example, Korean forms of parental involvement include an emphasis on private tutors (Park, Byun, \& Kim, 2011) and a much higher level of home-based involvement compared to school-based involvement (Kim, 2002). Korean culture places extremely high importance on education, even being portrayed as "obsessed" with children's educational success $(\mathrm{Oh}, 2010)$. This high emphasis on education combined with high levels of home-based parental involvement are reflected in the stereotype of the Asian "tiger mom", an authoritarian parent with too much involvement in their children's education. Inspired by this situation, we considered the question of the effectiveness of parental involvement in relation to children's attitudes towards their parents.

In this study, we particularly wanted to see whether children's attitudes toward their parents and parental involvement might be factors that restrain the relationship between parental involvement and children's English proficiency. Although parental involvement is generally known to have a positive correlation with academic success in language learning, no study to date has examined whether and how students' attitudes towards parental involvement influence the positive effect associated with parental involvement. The following research questions were asked in this study:

1) What are the types and degrees of parental involvement perceived by Korean EFL children? And what are the overall relationships between parental involvement of different types and children's English proficiency?

2) Does the relationship between parental involvement and children's English proficiency vary depending on children's attitudes towards their parents in general or/and towards parental involvement? If it does vary, in what ways? 


\section{Literature Review}

\subsection{Parental Involvement and Learners' Academic Achievement}

Parental involvement can be seen in terms of parental practices to help children's academic and intellectual activities. While Epstein (1995) includes six categories (basic parenting, facilitating learning at home, communicating with the school, volunteering at the school, participating in school decision-making, and collaborating with the community), parental involvement is often divided into two basic types, school-based and home-based involvement. School-based involvement generally requires parents' actual contact with schools (e.g., participating in school events or school organizations, communicating with teachers, volunteering at school) whereas home-based involvement takes place outside of school (e.g., helping children with homework, reading with children, encouraging academic success, talking with children about academic issues, expressing high educational expectations). Numerous studies have shown that both school-based and home-based types of parental involvements are positively correlated with academic outcomes (e.g., Grolnick \& Ryan, 1989; Hill, 2001; Hill et al., 2004, for school-based involvement, and Grolnick \& Slowiaczek, 1994; Hickman, Greenwood, \& Miller, 1995; Izzo et al., 1999, for home-based involvement). Home-based parental involvement and school-based involvement may be linked, as knowledge gained at parent-teacher meetings may be used in effective home-based involvement (Pomerantz et al., 2007).

Although the majority of the literature supports the positive relationship between parental involvement and children's academic achievement, several studies suggest that some types of involvement may have no effect, or even a negative effect in certain contexts. For example, Altschul (2012), Jeynes (2007) and Mau (1997) found that parents' assistance in homework produces non-significant or negative results for academic achievement. While these three studies all focused on adolescents, rather than young children, two of the studies found positive effects for other types of home-based involvement.

Pomerantz et al. (2007) also note that more involvement is not always better. They describe several ways in which specific types of parental involvement may have very different effects. For one thing, the success of parental involvement may vary depending on whether the involvement seeks to control a child's behavior or works to encourage autonomy (see also Pomerantz \& Ruble, 1998; Rollins \& Thomas, 1979). In distinguishing between autonomy-supportive vs. controlling involvement, Pomerantz et al. (2007, p. 381) define autonomy-supportive involvement as "allowing children to explore their own environment, initiate their own behavior, and take an active role in solving their own problems." Controlling forms of involvement, on the other hand, attempt to regulate children to produce particular outcomes by using directives and commands. In home-based involvement, an example of a controlling form of involvement would be forcing children to follow a set home-study schedule whereas autonomy-supportive involvement would not directly intervene in scheduling a child's study process. Pomerantz et al. suggest that parents' autonomy-supportive involvement, but not controlling involvement, enhances children's performance in school as it provides children with the experience of solving challenges themselves and heightens their intrinsic interest.

Another important distinction is that of process-focused versus person-focused involvement (Pomerantz et al., 2007; Pomerantz, Ng, \& Wang, 2006). Process-focused forms of involvement are those that emphasize the act of learning, such as focusing on study habits and the process of mastering specific skills. Person-focused forms of involvement are those that emphasize a child's innate abilities (such as intelligence) and outcomes (such as performance). Because person-focused types of involvement places more importance on what a child already possesses, types of efforts and the learning process itself are often disregarded. This may result in lost opportunities for developing motivation and specific skills (Hokoda \& Fincham, 1995).

Parental involvement is also recognized as a factor that may enhance children's achievement in language learning (Baird, 2015; Hill \& Tyson, 2009). With regard to students learning English in EFL contexts specifically, studies generally found a positive relationship between parental involvement and students' L2 English competence. Midraj and Midraj (2011) reported that parents' provision of learning resources had significant association with English reading comprehension and reading accuracy for fourth-grade EFL students. Hosseinpour, Yazdani, and Yrahmaadi (2015) found that, in an Iranian EFL context, parents' involvement in and attitudes toward their children's English language program correlated with children's achievement in the program. Morris et al. (2013) found that parental encouragement was positively associated with Korean high school EFL learners' English competence as well as with their motivation to learn.

\subsection{Affective Variables Associated with Parental Involvement}

Motivation and attitudes have been widely studied as important affective variables that are related to learners' achievement of language competence. Gardner (1985) defines motivation in L2 learning as the extent to which 
the learner strives to learn the L2 because of a desire to learn the language and the satisfaction gained from the learning experience. Often viewed as one of the most important variables for predicting language competence (Masgoret \& Gardner, 2003), learner motivation also explains why parental involvement correlates with learner success in language learning. Pomerantz et al. (2007) summarized two sets of models to explain the ways in which parents' involvement influences children: skill development models and motivational development models. While skill development models explain children's improved competence as due to skill-related resources provided by parents, motivation development models explain achievement through motivational resources provided by parents such as the intrinsic reasons for pursuing academics, a sense of control over academic performance, and positive perceptions of academic competence. These motivational resources allow children to see the learning tasks and their own competence in positive ways, leading to a higher level of achievement. Some studies have examined the role of motivation as connecting parental involvement and learner achievement. Gonzalez-Pienda et al. (2002), for example, present a structural equation model in which parental involvement influences learners' academic achievement by elevating learner's motivation (Also see Balli, Demo, \& Wedman, 1998).

Another important variable associated with the learner's achievement is attitude, which may be defined as a set of relatively enduring beliefs and emotions around a person, an object, or an event (Hogg \& Vaughn, 2005, p. 150 ). With respect to language learning, a variety of different attitudes have been examined to see how they are linked to students' motivation and achievement. Gardner (2007) hypothesized that students' motivation for language learning was influenced by attitudes toward their learning situation, including the program, teacher, peer students, materials, class atmosphere, and so on. As motivation is undoubtedly one of the most important factors that may predict the learners' language success, a learner's attitude towards different learning situations is also an important factor related to educational achievement.

In light of the importance of the learner's attitudes in achieving educational goals, and given that parental involvement is a basic part of educational contexts in many Asian countries, it is legitimate to examine how children's attitudes towards parental involvement interact with success in English language learning. While considerable number of studies examined the parental factors that may affect effects of parental involvement in children's education (e.g., about effects of parents' attitudes- Duber \& Epstein, 1993; about effects of parent's motivations for parental involvement- Green et al., 2007; about parent's beliefs and expectations regarding children-Parsons, Adler, \& Kaczala, 1982; about parents' cultural values or beliefs about their role in educationDe Gaetano, 2007), little research has been done to examine affective factors on the children's side that may influence the success of parental involvement. The effectiveness of parental involvement has not been examined in relation to children's attitudes towards their parents in general or towards parental involvement specifically. This paper seeks to examine Korean EFL learners' perceptions of parental involvement and how their attitudes toward parents and/or parental involvement are associated with the success of parental involvement.

\section{Methods}

\subsection{Subjects}

Participants were 254 sixth graders from two public elementary schools in a metropolitan city in South Korea. The students ranged from 11 to 12 years of age and included 130 girls and 124 boys. All of the students have taken formal English courses in school beginning in the third grade. However, it is common for children in Korea to begin studying English privately before the third grade, and we assume that many of the participants studied English before beginning formal classes in school. A background survey also indicated that $74 \%$ of the participants were currently studying English outside of school, either through private English tutoring or by attending one (or more) private English language academies. A total of 268 children initially participated in the study, but data from 14 children were excluded because they did not take the survey questionnaire seriously or failed to take the subsequent English proficiency test.

\subsection{Materials and Data Collection}

The present study collected data through 1) an attitude survey questionnaire; 2) a perceived parental involvement questionnaire; and 3) an English proficiency test.

\subsubsection{Attitude Survey Questionnaire}

Our attitude survey distinguished between two dimensions: Children's attitudes toward parents in general (10 items) and children's attitudes toward parental involvement in education (8 items). The first set of questions asked children about their general and integrative attitudes toward their parents (for example, my parents are nice people; I like my parents). The second set of questions dealt directly with children's attitudes toward 
parental involvement in their language learning. These questions gauged the degree to which children appreciate or approve of parental involvement in their English language studies (e. g., I think my parents' involvement in my study is helpful; I like my parents helping me with my homework from school or from my English academy). Each item was accompanied by a 5-point Likert scale in which children indicated their level of agreement (1=strongly disagree, $5=$ strongly agree). Children's responses above the point 3 were considered as indicating a positive attitude and the response below the point 3 a negative attitude in our analysis. The reliability coefficient of question items for the general attitude toward parents was .842 and the reliability coefficient for the attitude toward parental involvement was .866 .

\subsubsection{Perceived Parental Involvement Questionnaire}

We conducted a preliminary survey before constructing the parental involvement questionnaire. In the preliminary survey, 59 sixth grade students participated in a brief brainstorming session in which they were asked to write down any parental involvement activities they had experienced. The preparation of questionnaire items through this brainstorming process was chosen in order to better capture Korean parents' involvement behaviours that might not be considered in studies conducted in other countries. From the list of parental involvement behaviours obtained during the brainstorming session, we identified seven categories of involvement types: 1) Direct Assistance; 2) Managing and Monitoring; 3) Information Provision; 4) Study Environment Promotion; 5) Private Education Support; 6) Parents' Encouragement; and 7) Parents' Questions.

Using the results of the student brainstorming session, we constructed questionnaire items to reflect each of the seven types of parental involvement. Again, a 5-point Likert scale was used for children's responses to these items. Direct Assistance question items asked about parents' direct help in children's English learning. This category included activities such as helping children with their homework or helping children to prepare for English language exams. Managing and Monitoring items asked about parents' involvement in planning, organizing, or monitoring the ways in which their children study English. This category included activities such as setting study schedules for their children or checking to ensure that homework was completed. Information Provision items were concerned with parents' efforts to provide their children with information concerning language learning strategies. Study Environment Provision items were about parents' efforts in providing home environment favorable for English learning. This would include things like equipping them with English books at home and creating a quiet home atmosphere during English test preparation. Private Education Support items measured parents' support in providing children with private English lessons outside of school. This usually involves searching and contact English language academies or tutors for their child, paying tuition to the academy or the tutor, and motivating (or forcing) children to take private lessons. Parents Encouragement items asked about parents' encouragement and reinforcement of children's achievements, such as complimenting their children when they see them studying English. Parents' Questions items were intended to measure parents' efforts to initiate communication with their children. These question items asked whether parents ask their children questions concerning what they have learned in English class or how they are doing in the English classes at school. Table 1 shows an example question for each parental involvement type, the number of question items in each type, and reliability coefficients.

Table 1. Perceived parental involvement types, examples, and reliability coefficients

\begin{tabular}{llcc}
\hline Type of Involvement & Question Example & $\begin{array}{c}\text { No. of } \\
\text { items }\end{array}$ & $\begin{array}{c}\text { Reliability } \\
\text { Coefficients }\end{array}$ \\
\hline Direct Assistance & My parents help me with my English homework. & 5 & .832 \\
$\begin{array}{l}\text { Managing and } \\
\text { Monitoring }\end{array}$ & My parents set the study schedule for my English learning. & 5 & .645 \\
$\begin{array}{l}\text { Study Environment } \\
\text { Promotion }\end{array}$ & $\begin{array}{l}\text { My parents try not to invite their friends or relatives during } \\
\text { my exam periods or study hours. }\end{array}$ & 5 & .691 \\
$\begin{array}{l}\text { Information } \\
\text { Provision }\end{array}$ & $\begin{array}{l}\text { My parents gather information on how to study English } \\
\text { effectively and tell me about it. }\end{array}$ & 5 & .772 \\
$\begin{array}{l}\text { Private Education } \\
\text { Support }\end{array}$ & $\begin{array}{l}\text { My parents give me opportunities for private education such } \\
\text { as English academy and English tutoring. }\end{array}$ & 5 & .726
\end{tabular}




$\begin{array}{llcl}\text { Parents } & \text { My parents compliment me when they see me studying } & 5 & .734 \\ \text { Encouragement } & \text { English. } & & \\ \text { Parents' } & \text { My parents ask questions about what I have learned in } & 5 & .758 \\ \text { Questions } & \text { English classes. }\end{array}$

\subsubsection{English Proficiency Test}

To measure children's English proficiency, we employed the Test of the Skills in the English Language (TOSEL). The TOSEL test was developed in South Korea in 2004 and has been widely used for the assessment of children's English proficiency in South Korea. It has also been used in studies of English language teaching in Korea because it follows the public school curriculum and its multiple versions make it possible to closely fit the exam to specific learner abilities (Chung, 2010). The TOSEL exam has six versions intended for specific levels of learners' cognitive and English proficiency skills (for example, 'TOSEL Advanced' version for adults and higher level high school students and 'TOSEL Starter' version for 1st and 2nd grade children). For this study, we used TOSEL Junior version designed for target test takers in the fifth and sixth grade. This version consists of two sections. The first section assesses children's listening comprehension skills and their knowledge needed to respond and retell what they have heard. The second section tests reading comprehension skills and the knowledge needed for simple writing tasks.

\subsubsection{Procedure}

The questionnaires were distributed during the children's regular English classes at school. An English proficiency test that assessed children's English achievement was also administered in regular English classes, but was given several days after the questionnaire surveys were administered.

\section{Results}

\subsection{Overall Results}

Table 2 shows the descriptive statistics on participants' attitudes, perceived parental involvement, and their English proficiency.

Table 2. Descriptive statistics on children's attitudes, perceived parental involvement, and English proficiency

\begin{tabular}{lllll}
\hline & & Mean & SD & Range \\
\hline \multirow{2}{*}{ Attitudes } & Attitude toward Parents in General (APG) & 4.20 & 0.65 & $2.37-5.0$ \\
& Attitude toward Parental Involvement (API) & 3.21 & 0.79 & $1.0-5.0$ \\
\hline \multirow{4}{*}{ Perceived Parental Involvement } & Direct Assistance (DA) & 3.22 & 0.59 & $1.69-4.62$ \\
& Managing and Monitoring (MM) & 3.26 & 0.62 & $1.60-5.0$ \\
& Information Provision (IP) & 3.23 & 0.66 & $1.40-4.72$ \\
& Study Environment Promotion (SEP) & 3.27 & 0.74 & $1.40-5.0$ \\
& Private Education Support (PES) & 3.16 & 0.59 & $1.20-4.56$ \\
& Parents' Encouragement (PE) & 3.37 & 0.67 & $1.26-4.89$ \\
& Parents' Questions (PQ) & 3.32 & 0.63 & $1.40-4.69$ \\
\hline English Proficiency & English Proficiency Score (EPS) & 61.66 & 24.14 & $4.50-97.0$ \\
\hline
\end{tabular}

The mean score of children's attitude toward parents in general (APG) was 4.20, indicating that, on average, participants' general attitudes toward their parents are highly positive. The mean score of children's attitude toward parental involvement in their English learning (API) was 3.21. Although still positive (as it is above the point 3), this score was low compared to children's general attitudes toward their parents. With regard to the degree of parental involvement for different involvement types, parents are reportedly involved in all seven types to similar degrees. While Parents' Encouragement was the highest and Private Education Support was the lowest in terms of mean score, the mean scores of the seven types were concentrated within a small range between 3.16 and 3.37. This result suggests that, on average, our participants perceived the moderate degree of parental involvement similarly 
for all seven types.

Table 3 shows the correlations among the children's attitudes, perceived parental involvement of different types, and children's English proficiency.

Table 3. Correlations among the children's attitudes, perceived parental involvement, and English proficiency

\begin{tabular}{lllllllllll}
\hline & APG & API & DA & MM & IP & SEP & PES & PE & PQ & EPS \\
\hline Attitude: Parents in General (APG) & 1 & & & & & & & & & \\
Attitude :Parental Involvement (API) & $.60^{* *}$ & 1 &. & & & & & & & \\
Direct Assistance (DA) & $.35^{* *}$ & $.43^{* *}$ & 1 & & & & & & & \\
Managing \& Monitoring (MM) & $.30^{* *}$ & $.35^{* *}$ & $.94^{* *}$ & 1 & & & & & & \\
Information Provision (IP) & $.32^{* *}$ & $.42^{* *}$ & $.95^{* *}$ & $.96^{* *}$ & 1 & & & & & \\
Study Environment Promotion (SEP) & $.34^{* *}$ & $.41^{* *}$ & $.91^{* *}$ & $.87^{* *}$ & $.92^{* *}$ & 1 & & & & \\
Private Education Support (PES) & $.31^{* *}$ & $.40^{* *}$ & $.96^{* *}$ & $.94^{* *}$ & $.97^{* *}$ & $.90^{* *}$ & 1 & & & \\
Parents' Encouragement (PE) & $.30^{* *}$ & $.36^{* *}$ & $.91^{* *}$ & $.93^{* *}$ & $.87^{* *}$ & $.90^{* *}$ & $.86^{* *}$ & 1 & & \\
Parents' Questions (PQ) & $.35^{* *}$ & $.42^{* *}$ & $.95^{* *}$ & $.96^{* *}$ & $.96^{* *}$ & $.91^{* *}$ & $.96^{* *}$ & $.96^{* *}$ & 1 & \\
English Proficiency Score (EPS) & .04 & .05 & $.28^{* *}$ & $.26^{* *}$ & $.30^{* *}$ & $.31^{* *}$ & $.30^{* *}$ & $.28^{* *}$ & $.29^{* *}$ & 1 \\
\hline
\end{tabular}

Note: $* *$ indicates a significance of $\mathrm{p}<.01$.

Significant correlations (all at $\mathrm{p}<.01$ ) were found between English proficiency score and all seven types of parental involvement, among all seven types of parental involvement, between the attitudes toward parents in general (APG) and the attitude toward parental involvement (API), and between each of the two attitudes and all types of parental involvement. However, neither measure of children's attitudes (APG nor API) was significantly correlated with children's English proficiency scores.

The results suggest that all the parental involvement behaviors examined in the present study were positively correlated with children's English proficiency. They also showed that children who reported higher degrees of parental involvement had more positive attitudes towards their parents (both in general and in parental involvement). However, no direct correlation existed between the children's attitudes (APG and API) and their English proficiency.

\subsection{Results by Attitude Groups}

One of our research questions was to examine whether the relationship between the parental involvement and children's English proficiency changes depending on children's APG and/or API. However, due to the extremely skewed responses for APG questionnaire items, it was not possible to use our APG data to answer this research question. As shown in Table 2, our participants responded very positively on the questions asking their attitude towards their parents in general (mean: 4.20). Indeed, only 14 among 254 participants responded below 3.0. This suggests that the participants either had highly positive attitudes towards their parents or did not feel comfortable providing negative assessments of their parents. This result is not particularly surprising, as showing parental respect is a core value in Korean family socialization (Choi et al., 2013). However, this result did not allow us to investigate whether children's negative attitudes toward their parents might change the relationship between the parental involvement and children's achievement.

Because the participants' API scores (Mean: 3.21) showed a rather normal distribution, we were able to continue to pursue our question regarding the role of children's attitudes toward parental involvement. Based on their API scores, we divided our participants into five groups. Participants' z-scores of API score were used as cut-off points to define different API groups. Table 4 summarizes the descriptive statistics on the participants in the five groups. 
Table 4. Descriptive statistics for five API groups

\begin{tabular}{llllll}
\hline & $\mathrm{z}$ - score Range & API score Range & API score Mean & Proficiency Score Mean & No. of Subjects \\
\hline Group 1 & $+1<\mathrm{z}$ & $4.0-5.0$ & 4.34 & 64.13 & 48 \\
Group 2 & $+0.3<\mathrm{z} \leq+1$ & $3.5-3.9$ & 3.64 & 63.74 & 48 \\
Group 3 & $-0.3 \leq \mathrm{z} \leq+0.3$ & $3.0-3.4$ & 3.17 & 56.14 & 68 \\
Group 4 & $-1 \leq \mathrm{z}<-0.3$ & $2.5-2.9$ & 2.72 & 66.44 & 54 \\
Group 5 & $\mathrm{z}<-1$ & $1.0-2.4$ & 1.9 & 58.88 & 36 \\
\hline
\end{tabular}

The cut-off levels of z-scores \pm 1 were chosen because they identify participants who substantially deviate from the mean while still providing adequate number of subjects for Group 1 (a highly positive API Group) and Group 5 (a highly negative API Group). The cut-off levels \pm 0.3 were chosen because a z-score of -0.3 distinguished those with positive attitude toward parental involvement (i.e., those whose API score were above 3 ) from those with negative attitude toward parental involvement (i.e., those whose API score were below 3). Choosing a cut-off level of a z-score \pm 0.3 also ensured relatively balanced number of subjects among Group 2 (intermediately positive API Group), Group 3 (moderately positive API Group), and Group 4 (moderately negative API Group).

A One-way ANOVA and series of post-hoc analyses conducted on API scores of these five groups indicated that each group's API score mean is significantly different from those of the other four groups $(\mathrm{F}=671.926, \mathrm{p}<.001)$. The differences in means of the English proficiency scores among the five groups were not significant $(\mathrm{F}=1.771, \mathrm{p}>.05)$.

In order to examine the relationship between the parental involvement and children's English proficiency in each API Group, a correlation analysis was conducted for each group. Table 5 shows the results.

Table 5. Correlations of parental involvement and children's English proficiency in five API groups

\begin{tabular}{lccccccc}
\hline & DA & MM & IP & SEP & PES & PE & PQ \\
\hline $\begin{array}{l}\text { Group 1 } \\
\text { English Proficiency }\end{array}$ & $.38^{* *}$ & $.34^{*}$ & $.35^{*}$ & $.32^{*}$ & $.38^{* *}$ & $.33^{*}$ & $.33^{*}$ \\
$\begin{array}{l}\text { Group 2 } \\
\text { English Proficiency }\end{array}$ & $.37^{*}$ & $.37^{* *}$ & $.38^{* *}$ & $.41^{* *}$ & $.42^{* *}$ & $.35^{*}$ & $.34^{*}$ \\
$\begin{array}{l}\text { Group 3 } \\
\text { English Proficiency }\end{array}$ & $.26^{*}$ & $.29^{*}$ & $.27^{*}$ & $.30^{*}$ & $.32^{* *}$ & $.30^{*}$ & $.30^{*}$ \\
$\begin{array}{l}\text { Group 4 } \\
\text { English Proficiency }\end{array}$ & 0.2 & 0.24 & $.28^{*}$ & $.36^{*}$ & 0.2 & $.29^{*}$ & 0.26 \\
Group 5 & & & & & & & \\
English Proficiency & 0.15 & -0.03 & 0.24 & 0.19 & 0.13 & 0.07 & 0.2 \\
\hline DA: Dirt Assing
\end{tabular}

DA: Direct Assistance, MM: Managing \& Monitoring, IP: Information Provision, SEP: Study Environment Promotion, PES: Private Education Support, PE: Parents' Encouragement, PQ: Parents' Questions

Note: *indicates a significance of $p<.05$ and **indicates a significance of $p<.01$.

In Group 1 (the highly positive API group), Group 2 (the intermediately positive API group), and Group 3 (the moderately positive API group), children's English proficiency was significantly correlated with all seven types of parental involvement. Thus, for participants with positive attitude towards parental involvement, all forms of parental involvement were positively correlated with English proficiency. In Group 4 (the moderately negative API group), children's English proficiency was significantly correlated with only three types of involvement: Information Provision, Study Environment Promotion, and Parents' Encouragement, but not with the other types of parental involvement. In Group 5 (the highly negative API group), none of the parental involvement types were shown to be significantly correlated with the children's proficiency. These results suggest that the relationship between the parental involvement and children's English proficiency change depending on the participants' attitude 
towards parental involvement.

\section{Discussion}

One of our research questions was to investigate the types and degrees of parents' involvement in their children's English learning in Korea. We identified seven types of parental involvement through a preliminary survey from $6^{\text {th }}$ grade children: Direct Assistance, Managing \& Monitoring, Information Provision, Study Environment Promotion, Private Education Support, Parents' Encouragement, and Parents' Questions. These forms of involvement emerged from the brainstorming session and were similar to the patterns found in other studies of parental involvement in Korean and Korean-American families (e.g., Park et al., 2011; Kim, 2002). In particular, most forms of parental involvement perceived by the participants were home-based involvement, which is in consistent with other studies involving Korean families (Kim, 2002). This contrasts with involvement patterns in the United States, where school-based involvement is more common. Similarly, the use of private tutors or English academies outside of school was reported by a number of children, a phenomenon also found in other studies with Korean parental involvement (Park et al., 2011).

Our results indicated that the degree of perceived parental involvement was similar across all seven types of involvement. On average, children reported that they perceived moderate degrees of parental involvement (between 3.16 and 3.37) both for rather direct types of involvement such as Direct Assistance and Managing and Monitoring and for indirect types of involvement such as Information Provision, Study Environment Promotion, Parents' Encouragement, and Parents' Questions.

With respect to the Korean children's attitudes, on average, Korean children showed highly positive attitude toward their parents in general (mean: 4.20) and slightly positive attitudes towards parental involvement (3.21). Children's positive attitude towards parental involvement, although marginal, is somewhat unexpected considering negative ("Tiger Mom") stereotypes of Asian parenting styles as overly harsh. The present results seem to suggest that Korean children's attitudes towards parental involvement are not as negative as often assumed. In fact, Choi et al. (2013) describe Korean American parenting styles as authoritative but also highly positive (in terms of warmth, acceptance, or communication), implying that the stereotype of "harsh" parenting does not reflect all aspects of Korean parents' behavior. Moreover, in our study, those children who reported higher degree of parental involvements had better attitudes towards their parents in general and towards parental involvement. This result suggests that, contrary to the popular idea that Asian mothers' excessive involvement in education could be the source of bad parent-child relationships, high parental involvement be unrelated to children's negative attitude towards their parents or parental involvement, at least with respect to language learning.

In regard with the overall relationship between the perceived parental involvement and children's English proficiency, positive correlations were found between all types of parental involvement and children's English proficiency. This result generally conforms to the results of the other studies involving young children that most types of parental involvement are positively associated with academic achievement in general (for example, Driessen et al., 2005; Fan \& Chen, 2001). The result is also consistent with Morris et al. (2013)'s study with Korean high schoolers, which found a correlation between parental encouragement and learners' English competence. Park et al. (2011)'s longitudinal study also showed that private tutoring was significantly correlated with Korean seventh grade students' achievement.

Our main research question was to investigate the role of children's attitudes toward parents in general (APG) and children's attitudes toward parental involvement (API) in establishing the relationship between parental involvement and children's English proficiency. While it was difficult to examine the role of children's APG with the present data due to the extremely skewed children's APG scores, the role of children's API was examined by comparing five groups of different API levels. The results showed that children's English proficiency was positively correlated with all seven types of parental involvement in the three groups with positive API (Groups 1, 2, and 3), and with three types of parental involvement in moderately negative API group (Group 4), but not with any type of parental involvement in highly negative API Group (Group 5). That is, the significant positive correlation between children's English proficiency and all types of parental involvement shown to exist in the groups with positive API does not hold in the groups with negative API. These results enable us to hypothesize that the benefit of parents' involvement could be moderated by children's attitude toward parents' involvement: Parental involvement may be most beneficial when children take positive attitudes towards their parents' involvement in their language learning process. When children's attitudes are moderately negative, this positive effect may occur selectively, depending on the specific type of assistance parents provides. When children have highly negative attitudes, the positive effect of parental involvement disappears regardless of the type of parental involvement.

This finding may contribute to the view that the effects of parenting are partly determined by the characteristics of 
children (e.g., Colder, Lochman, \& Wells, 1997; Grusee, 2002; Kochanska, 1993). The present results suggest that children's attitudes could be a factor that constrains the relationship between the parental involvement and children's achievement. That is, what children bring toward parental involvement may be as important as what parents bring to their children. While a wide range of different types of home-based parental involvement have been studied and many of them are known to be associated with children's academic achievement (e.g., see Fan \& Chen, 2001), not all children are sensitive to the known positive effects of parental involvement. The present results indicate that more attention must be paid to children's attitudes as an important factor that decides the success of parental involvement.

The result by the moderately negative API group (Group 4) needs particular attention. For those with moderately negative API, the effect of parental involvement on English proficiency was limited to certain types of involvement. If we hypothesize children's API as a kind of affective filter that restrains the positive effects of parental involvement, a moderate level of negative filter is certainly selective, permitting only certain types of involvement to go through it and blocking some others. The three types of parental involvement that showed correlation with English proficiency for this group were Information Provision, Study Environment Promotion, and Parents' Encouragement. When comparing these types with the ones that were not correlated with children's English proficiency, more indirect forms of parental involvement seem to be correlated with successful language learning for this group of children. By indirect types of involvement, we mean forms that are easier to foster autonomy and forms that are process-based. The survey questions associated with these types of involvement include providing a quiet place to study, providing information about study strategies, providing children with English-language books and study guides, and encouraging students for their efforts. In practicing these types of involvement, parents are more likely to promote children's autonomy in language learning. Questions in these categories also included process-focused forms of involvement (e.g. my parents tell me how to study English effectively) rather than person-focused involvement (e.g. my parents put emphasis on winning the competition with friends). Because of this indirect nature, these types of involvement may be less likely to interact with children's negative attitudes toward parental involvement. On the other hand, involvement types such as Direct Assistance, Managing \& Monitoring, and Private Education Support could be more direct and controlling, and thus probably are more likely to interact with children's negative attitudes. For example, while helping children with their homework could be beneficial as it may provide children with skill-related information, it could also hurt children's autonomy if parents are controlling and too directive. Likewise, private education in Korea is mostly arranged (and often forced) by parents, leaving little room for children to make their own decisions about their educational goals and strategies. There are a number of studies pointing out that parents' autonomy support helps children achieve higher academic performance, but parents' control hinders it (e.g., Ginsburg \& Bronstein, 1993; Ng et al., 2004). The present results seem to imply that children's impaired autonomy may be particularly bad when children have negative API, delimiting the positive effect of parental involvement even for children with mildly negative API.

The present result is also supported in part by the longitudinal study carried out by Steinberg et al. (1992) which found that parental involvement is correlated with higher achievement among adolescents when parents were perceived as authoritative (high acceptance, supervision, and psychological autonomy granting) than authoritarian (high controlling and low autonomy granting). While this study does not deal with children's attitude as an independent variable related to the success of parental involvement, it adopted children's perception of parenting style as a factor associated with successful parental involvement. It also points to the importance of autonomy-supportive parental involvement, which was proven through the moderately negative API group in our study.

It must be noted, however, that 'Parents Questions', which could be seen as indirect type of involvement, was not correlated with children's English proficiency in the moderately negative API group. This result would be not consistent with the results of the other indirect types of involvement. One possible reason for this would be that some of the question items in this category could have been unintentionally interpreted by children as asking about parents' managing and monitoring behaviours. The question items in this category included 'My parents ask me about what I have learned from English class at school or language academy', 'My parents often ask me whether I am studying English hard,' and 'My parents ask me about how I am doing in school.' To some children, these questions could have been viewed as another form of checking and controlling their behaviour, not as genuine information-seeking questions. Especially for the children with negative API, these sorts of questions might have been perceived as showing parents' distrust of their academic endeavours or as a form of indirect criticism for not studying harder, rather than as an expression of parents' love and care, or parents' effort to communicate with them.

\section{Conclusion}

The results of the current study suggest the possibility that learners' attitudes toward parental involvement might 
be a factor that delimits the positive influence of parental involvement on EFL learners' achievement: While all seven forms of parental involvement promote success for students with positive attitudes towards parental involvement, this was not the case for the students with negative attitudes toward parental involvement.

The results are also indicative of the importance of autonomy-supporting and process-focused parental involvement. Children with moderately negative attitudes were responsive only to the indirect types of parental involvement such as Information Provision, Study Environment Promotion, and Parents' Encouragement. From a different point of view, this result could also be seen as further indicating the importance of children's' attitudes: When children perceive their parents' interventions in a positive way, even those types of involvement which could be seen as less autonomy-supportive and more controlling (such as Managing and Monitoring) are positively correlated with children's achievement, at least in Korean EFL situation.

Children's attitudes are probably more important than we have traditionally thought. What children feel and think about their parents' attempts to help them may be as important as what parents do to help their children. One direction for future research on parental involvement, then, must be to find out how children form these attitudes toward parental involvement. While children's attitudes towards parental involvement could be influenced by their general attitudes toward parents, it also could be direct results of their previous experiences with parents' involvement behaviours. If it is the case, it would be important to investigate the manners and context of parental involvement that could help children develop positive attitudes towards their parental involvement within the given socio-cultural environment.

\section{Acknowledgments}

The present study was supported by the 2013 Research Grant of Incheon National University. We thank two graduate students at Incheon National University for their help in recruiting the participants of this study.

\section{References}

Altschul, I. (2012). Linking socioeconomic status to the academic achievement of Mexican American youth through parent involvement in education. Journal of the Society for Social Work and Research, 3, 13-30. https://doi.org/10.5243/jsswr.2012.2

Baird, A. S. (2015). Beyond the greatest hits: A counter story of English learner parent involvement. School Community Journal, 225(2), 153-175.

Balli, S. J., Demo, D. H., \& Wedman, J. F. (1998). Family involvement with children's homework: An intervention in the middle grades. Family Relations, 47, 149-157. https://doi.org/10.2307/585619

Choi, Y., Kim, Y., Kim, S., \& Park, I. K. (2013). Is Asian American parenting controlling and harsh? Empirical testing of relationships between Korean American and Western parenting measures. Asian American Journal of Psychology, 4(1), 19-29. https://doi.org/10.1037/a0031220

Chung, D-U. (2010). The effect of shadowing on English listening and speaking abilities of Korean middle school students. English Teaching, 65(3), 97-127. https://doi.org/10.15858/engtea.65.3.201009.97

Colder, C. R., Lochman, J. E., \& Wells, K. C. (1997). The moderating effects of children's fear and activity level on relations between parenting practices and childhood symptomatology. Journal of Abnormal Child Psychology, 25, 251-263. https://doi.org/10.1023/A:1025704217619

Driessen, G., Smit, F. \& Sleegers, P. (2005). Parental involvement and educational achievement. British Educational Research Journal, 31(4), 509-532. https://doi.org/10.1080/01411920500148713

Dauber, S. L., \& Epstein, J. L. (1993). Parents' attitudes and practices of involvement in inner-city elementary and middle schools. In N. Chavkin (Ed.), Families and schools in a pluralistic society (pp 53-71). New York: SUNY Press.

Epstein, J. L. (1995). School/family/community partnerships: Caring for the children we share. Phi Delta Kappan, 76(9), 701-712. https://doi.org/10.1177/003172171009200326

Fan, X., \& Chen, M. (2001). Parental involvement and students' academic achievement: A meta-analysis. Educational Psychology Review, 13(1), 1-22. https://doi.org/10.1023/A:1009048817385

Gardner, R. C. (1985). Social psychology and second language learning: The role of attitudes and motivation. London: Arnold.

Gardner, R. C. (2007). Motivation and second language acquisition. Porta Linguarum, 8, 9-20.

Ginsburg, G. S., \& Bronstein, P. (1993). Family factors related to children's intrinsic/extrinsic motivational 
orientation and academic performance. Child Development, 64, 1461-1474. https://doi.org/10.1111/j.146 7-8624.1993.tb02964.x

Gonzalez-Pienda, J. A., Nunez, J. C., Gonzalez-Pumariega, S., Alvarez, L., Roces, C., \& Carcia, M. (2002). A structural equation model of parental involvement, motivational and aptitudinal characteristics and academic achievement. The Journal of Experimental Education, 70, 257-287. https://doi.org/10.1080/0022 0970209599509

Green, C. L., Walker, J. M., Hoover-Dempsy, K. V., \& Sandler, H. M. (2007). Parents' motivations for involvement in children's education: An empirical test of a theoretical model of parental involvement. Journal of Educational Psychology, 99(3), 532-544. https://doi.org/10.1037/0022-0663.99.3.532

Grolnick, W. S., \& Ryan, R. M. (1989). Parent styles associated with children's self-regulation and competence in school. Journal of Educational Psychology, 81, 143-154. https://doi.org/10.1037/0022-0663.81.2.143

Grolnick, W. S., \& Slowiaczek, M. L. (1994). Parents involvement in children's schooling: A multidimensional conceptualization and motivational model. Child Development, 65(1), 237-252. https://doi.org/10.1111/j.14 67-8624.1994.tb00747.x

Grusee, J. F. (2002). Parenting socialization and children's acquisition of values. In M. H. Bornstein (Ed.), Handbook of parenting; Vol. 5: Practical issues in parenting (2nd ed., pp, 143-176). Mahwah, NJ: Lawrence Erlbaum.

Hickman, C. W., Greenwood, G. E., \& Miller, M. D. (1995). High school parent involvement: Relationships with achievement, grade level, SES, and gender. Journal of Research and Development in Education, 28, 125-134.

Hill, N. E. (2001). Parenting and academic socialization as they relate to school readiness: The role of ethnicity and family income. Journal of Educational Psychology, 93, 686-697. https://doi.org/10.1037/0022-0663.93. 4.686

Hill, N. E., Castellino, D. R., Lansford, J. E., Nowlin, P., Dodge, K. A., Bates, J. E., \& Pettit, G. S. (2004). Parent academic involvement as related to school behavior, achievement, and aspirations: Demographic variations across adolescence. Child Development, 75, 1491-1509. https://doi.org/10.1111/j.1467-8624.2004.00753.x

Hill, N. E., \& Tyson, D. F. (2009). Parental involvement in middle school: A meta-analytic assessment of the strategies that promote achievement. Developing Psychology, 45, 740-763. https://doi.org/10.1037/a00153 62

Hogg, M. A., \& Vaughan, G. M. (2005). Social Psychology (6th ed.). NJ: Prentice Hall.

Hokoda, A., \& Fincham, F. D. (1995). Origins of children's helpless and mastery achievement patterns in the family. Journal of Educational Psychology, 87(3), 375-385. https://doi.org/10.1037/0022-0663.87.3.375

Hosseinpour, V., Yazdani, S., \& Yrahmaadi, M. (2015). The relationship between parents' involvement, attitude, educational background and level of income and their children's English achievement test scores. Journal of Language Teaching and Research, 6(6), 1370-1378. https://doi.org/10.17507/jttr.0606.27

Izzo, C. V. Weissberg, R. P., Kasprow, W. J., \& Fendrich, M. (1999). A longitudinal assessment of teacher perceptions of parent involvement in children's education and school performance. American Journal of Community Psychology, 27(6), 817-839. https://doi.org/10.1023/A:1022262625984

Jeynes, W. (2007). The relationship between parental involvement and urban secondary school student academic achievement: A meta-analysis. Urban Education, 42(1), 82-110. https://doi.org/10.1177/0042085906293818

Jeynes, W. (2010). Parental involvement and academic success. New York, NY: Routledge. https://doi.org/10.43 24/9780203843444

Kim, E. (2002). The relationship between parental involvement and children's educational achievement in the Korean immigrant family. Journal of Comparative Family Studies, 33(4), 529-540.

Kochanska, G. (1993). Toward a synthesis of parental socialization and child temperament in early development of conscience. Child Development, 64, 325-347. https://doi.org/10.1111/j.1467-8624.1993.tb02913.x

Lamborn, S., Mounts, N. S., Steignberg, L., \& Donbusch, S. M. (1991). Patterns of competence and adjustment among adolescent from authoritative, authoritarian, indulgent, and neglectful families. Child Development, 62, 1049-1065. https://doi.org/10.1111/j.1467-8624.1991.tb01588.x

Masgoret, A. M., \& Gardner, R. C. (2003). Attitudes, motivation and second language learning: A meta-analysis 
of studies conducted by Gardner and associates. Language Learning, 53(1), 167-210. https://doi.org/10.11 $11 / 1467-9922.00212$

Mau, W. (1997). Parental influences on the high school student's academic achievement: A comparison of Asian immigrants, Asian Americans, and White Americans. Psychology in the Schools, 34(3), 267-277. https://doi.org/10.1002/(SICI)1520-6807(199707)34:3<267::AID-PITS9>3.0.CO;2-L

Midraj, J., \& Midraj, S. (2011). Parental involvement and grade four students' English reading achievement. International Journal of Applied Studies, 12(1), 41-56.

Morris, A., Lafontaine, M., Pichette, F., \& de Serres, L. (2013). Affective variables, parental involvement and competence among South Korean high school learners of English. Studies in Second Language Learning and Teaching, 3(1), 13-45. https://doi.org/10.14746/ssllt.2013.3.1.2

Ng, F. F., Kenney-Benson, G. A., \& Pomerantz, E. M. (2004). Children's achievement moderates the effects of mothers' use of control and autonomy support. Child Development, 75, 764-780. https://doi.org/10.111 1/j.1467-8624.2004.00705.x

Oh, I. (2010). Education and development: Why are Koreans obsessed with learning? Comparative Sociology, 9(3), 308-27. https://doi.org/10.1163/156913209X12499527665422

Park, H., Byun, S., \& Kim, K. (2011). Parental involvement and students' cognitive outcomes in Korea: Focusing on private tutoring. Sociology of Education, 84(1), 3-22. https://doi.org/10.1177/00380407 10392719

Parsons, J. E., Adler, T. F., \& Kaczala, C. M. (1982). Socialization of achievement attitudes and beliefs: Parental Influences. Child Development, 53(2), 310-321. https://doi.org/10.2307/1128974

Pomerantz, E. M., \& Ruble, D. N. (1998). The multidimensional nature of control: Implications for the development of sex differences in self-evaluation. In J. Heckhausen, \& C. S. Dweck (Eds.), Motivation and self-regulation across the lifespan (pp. 159-184). New York: Cambridge University Press. https://doi.org/10. 1017/CBO9780511527869.008

Pomerantz, E. M., Moorman, E. A., \& Litwach, S. D. (2007). The how, whom, and why of parents' involvement in children's academic lives: More is not always better. Review of Educational Research, 77(3), 373-410. https://doi.org/10.3102/003465430305567

Pomerantz, E. M., Ng, F., \& Wang, Q. (2006). Mothers' mastery-oriented involvement in children's homework: Implications for the well-being of children with negative perceptions of competence. Journal of Educational Psychology, 98, 99-111. https://doi.org/10.1037/0022-0663.98.1.99

Rollins, B. C., \& Thomas, D. L. (1979). Parental support, power, and control techniques in the socialization of children. In W. R. Burr, R. Hill, F. I. Nye, \& I. L. Reiss (Eds.), Contemporary theories about the family (pp. 317-364). New York: Free Press.

Steinberg, I., Lamborn, S. D., Dornbusch, S. M., \& Darling, N. (1992). Impact of parenting practices on adolescent achievement: Authoritative parenting, school involvement, and encouragement to succeed. Child Development, 63, 1266-1281. https://doi.org/10.1111/j.1467-8624.1992.tb01694.x

\section{Copyrights}

Copyright for this article is retained by the author(s), with first publication rights granted to the journal.

This is an open-access article distributed under the terms and conditions of the Creative Commons Attribution license (http://creativecommons.org/licenses/by/4.0/). 